\title{
LA EVOLUCION DE LA LANZA EN OCCIDENTE (PIEZAS DE HIERRO DE HALLSTATT AL SIGLO XV)
}

\author{
POR \\ JUAN-EDUARDO CIRLOT
}

DETERMINAR la evolución de la lanza es difícil, incluso en el área occidental. Fijar el período a que corresponde una determinada pieza con frecuencia implica los más graves problemas, y la posibilidad de error siempre está al acecho. Naturalmente, seriar cronológicamente lanzas de fecha determinada por hallazgos arqueológicos precisos: excavaciones de ruinas, tumbas, etc., es fácil. Pero aplicar los resultados que se obtienen con esta organización supuesta ya no lo es tanto. Ello se debe esencialmente a un hecho: la falta de caracterización estilística suficiente en gran númcro de piezas, aunque es innegable que hay otras cuya forma «dice» con claridad a qué mundo cultural pertenecen. Complementa esa falta de caracterización la riqueza tipológica que suele darse en cada período. El canon varía con libertad e igualmente las dimensiones e incluso la técnica. Para el coleccionista de lanzas, o para el investigador que se enfrenta con piezas que no proceden de hallazgos fechados, es muy arduo, pues, saber con aproximación a qué época y lugar corresponden tales armas. Tiene a su disposición varios elementos de juicio: la comparación con las armas procedentes de hallazgos fechados, la «calidad» (textura) de la pie$z a$, es decir, su aspecto táctil, que acaba por ser inconfundible o poco menos para el que frecuenta los objetos antiguos. Finalmente, por escasa que sea la «caracterización estilística», siempre hay alguna, y ayuda a corroborar o a rectificar las hipótesis formuladas con la base de los dos principios primeros.

La textura de las armas anteriores a nuestra era es rugosa y los efectos de la mordedura del óxido son profundos. Cierto es que hay lanzas del siglo $\mathrm{x}$ que pueden presentar una textura análoga, como se ve en las armas de la Edad del Hierro o del primer milenio de nuestra Era, que algunos museos «conservan» recubiertas de su capa doble de oxidación y de tierra petrificada o poco menos, una vez limpias - lo que casi siempre puede hacerse sin riesgos-, dado que el peso y grosor «indiquen» que bajo el color ocre de la pieza hay, la fuerza del hierro presta a mostrar su superficie refulgente.

Un ejemplo de la variedad tipológica de cada período lo tenemos en la figura 1, que presenta tipos de lanza de la época de Hallstatt, con las 
mayores diferencias entre sí, desde el pequeño hierro de pica, que puede tener de 8 a $12 \mathrm{~cm}$., o a veces menos, a la larga lanza de hoja plana y filos paralelos del centro, cuya longitud supera con frecuencia los $30 \mathrm{~cm}$. Las lanzas de Hallstatt, en general, tienen perfiles angulosos, aunque existen también las que ya preceden el más curvilíneo estilo de La Tène,

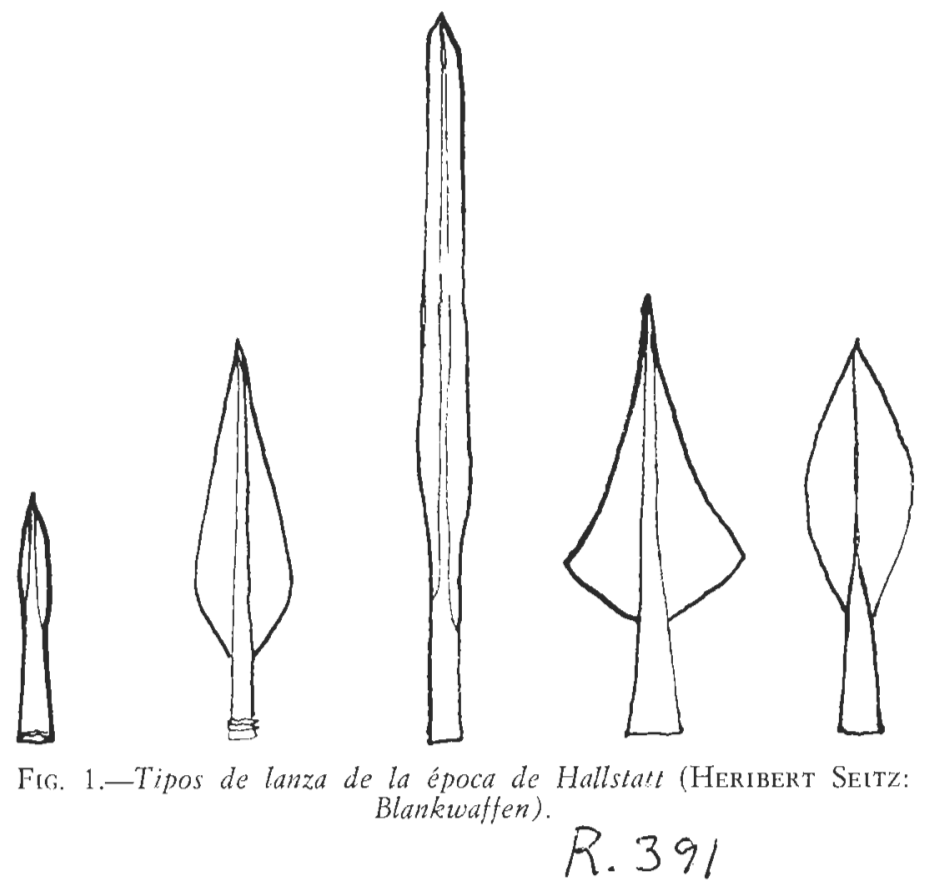

como se advierte en el último tipo, que aparece a la derecha. El libro de Heribert Seitz Blankwaffen, sin duda una de las mejores obras sobre armas escritas en los años últimos, es una valiosa contribución, por estos y otros ejemplos, a la historia de la evolución de la lanza. Tanto los pueblos helénicos como los itálicos pasaron del uso de armas de tipo hallstático o poshallstático al de armas La Tène. No otra cosa es la adquisición del gladius bispanicus, tan justamente debatida, por los romanos. Dejaron la espada en forma de hoja lanceolada por la de filos paralelos. Así, en la figura 2 copiamos ejemplos de lanzas griegas publicados por Snodgrass en su interesante libro Early Greek Armours and Weapons. Se advierte que estos tipos, de escasa determinación geográfica, se mueven entre los ejemplos de la figura 1. La lanza romana, dejando aparte el pilum, al que

6 
dedicaremos breves líneas al final de este texto, suele ser de tipo hallstático. Si en la espada los romanos encontraron conveniente crear un tipo recortando la longitud de la espada céltica de cuatro mesas y filos paralelos, en la lanza no se sintieron atraídos, al parecer, por las formas sinuosas y de bellas curvaturas de las distintas etapas de La Tène, a que

Fig. 2.-Tipos de lanzas griegas (hay de bronce y hierro). Epoca hallstática (ANTHONY SNODGRASS: Early Greck Armours and Weapons).
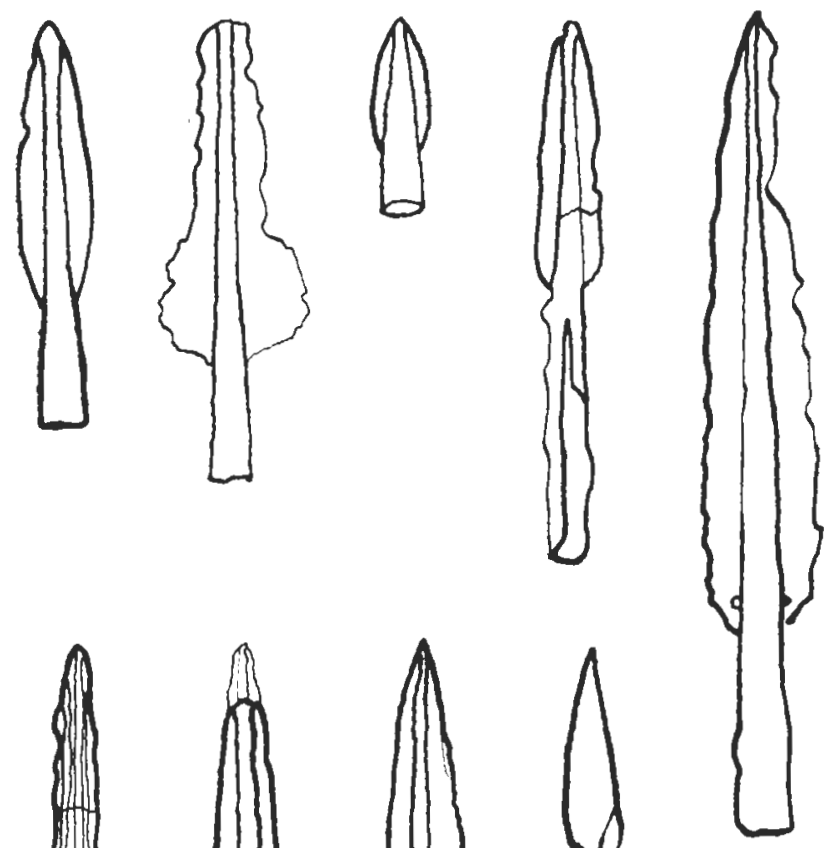

$$
\text { R. } 392
$$
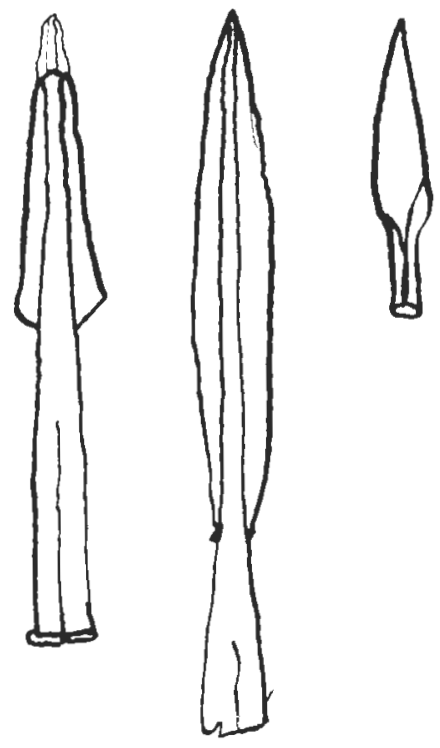
luego nos referiremos. Este tipo hallstático, si es que queremos darle esta denominación, que no siempre garantiza una absoluta diferenciación tipológica, prosiguió manteniéndose en el norte de Europa, y ya veremos que las lanzas de los vikingos siguen su tónica. Ignoramos si los romanos conocieron un tipo de lanza, de técnica muy perfecta, que ha sido hallado entre los francos, en el cual el tubo en que se encaja el asta no es cónico, sino piramidal, hexagonal u octogonal, prolongando sus líneas las de la

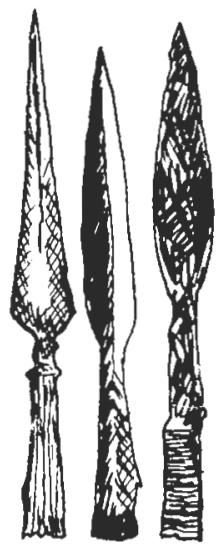

Fig. 3.-Lanzas ilalianas, de Talamone, probablemente romanas, de hacia 225 antes de Jesucristo. (Catálogo del British Museum.)

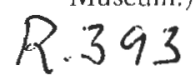

estructura de la hoja. Las lanzas romanas, de período imperial, seguramente fueron de los más diversos tipos, ya que cuanto más se ahonda en la historia del Imperio romano, más se advierte la variedad y riqueza del armamento (cota de malla, caparazones de protección para los caballos, yelmos con máscara usados en combate, etc.), en una evolución que duró doce siglos. Dentro de los tipos poshallstáticos parece que deben clasificarse muchas lanzas encontradas en España, algunas publicadas por Menéndez Pidal en el volumen II de su Historia de España. Suelen presentar algo redondeada la angulosidad lateral de la hoja, su tamaño corresponde claramente a uno de estos tres tipos: hoja corta y no muy ancha $(20 \mathrm{~cm}$. de promedio), hoja larga y estrecha (hay ejemplares con una nervadura nielada en plata, de longitud superior a los $40 \mathrm{~cm}$.) y lanzas de hoja relativamente corta y largo tubo, emparentadas con los pila (Fig. 4). Pese a lo tardío de las fechas, no suelen mostrar rasgos La Tène, y es sabido que los celtas que entraron en la Península eran portadores de una cultura poshallstática, aunque tuviera contaminaciones La Tène 
y ésta acabara por penetrar en las oleadas más tardías o por el simple contacto con los pueblos transpirenaicos.

Como decíamos antes, la lanza La Tène -acaso la etapa II es la más característica - se define por sus formas redondeadas, que siguen el mis-

FIG. 4.-Lanzas bispánicas. Siglos II-1 antes de Jesucristo (Menéndez Pidal: Historia de España, vol. If. 394
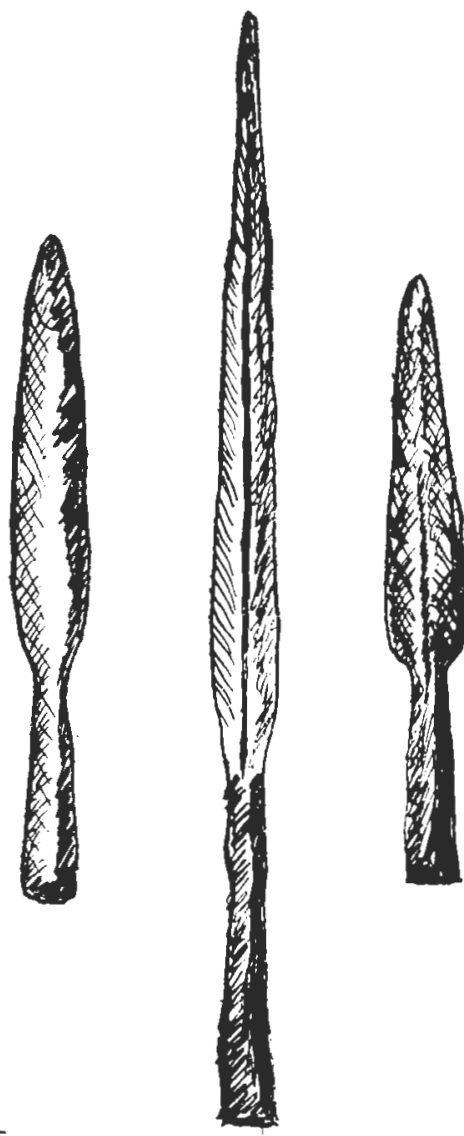

mo espíritu de la ornamentación céltica, opuesta a la de trazos más rectilíneos de Hallstatt. Las figuras 5 y 6 presentan lanzas de La Tène, tomadas del famoso manual de Déchelette. En la Baja Edad Media las hojas anchas y redondeadas volverán a aparecer, sobre todo desde el siglo xrv. 
Puede verse en los ejemplos antes aludidos que la variedad tipológica de La Tène es casi tan grande, al parecer, como la hallstática, suministrando incluso tipos «flamígeros», como los de las hojas de espada que
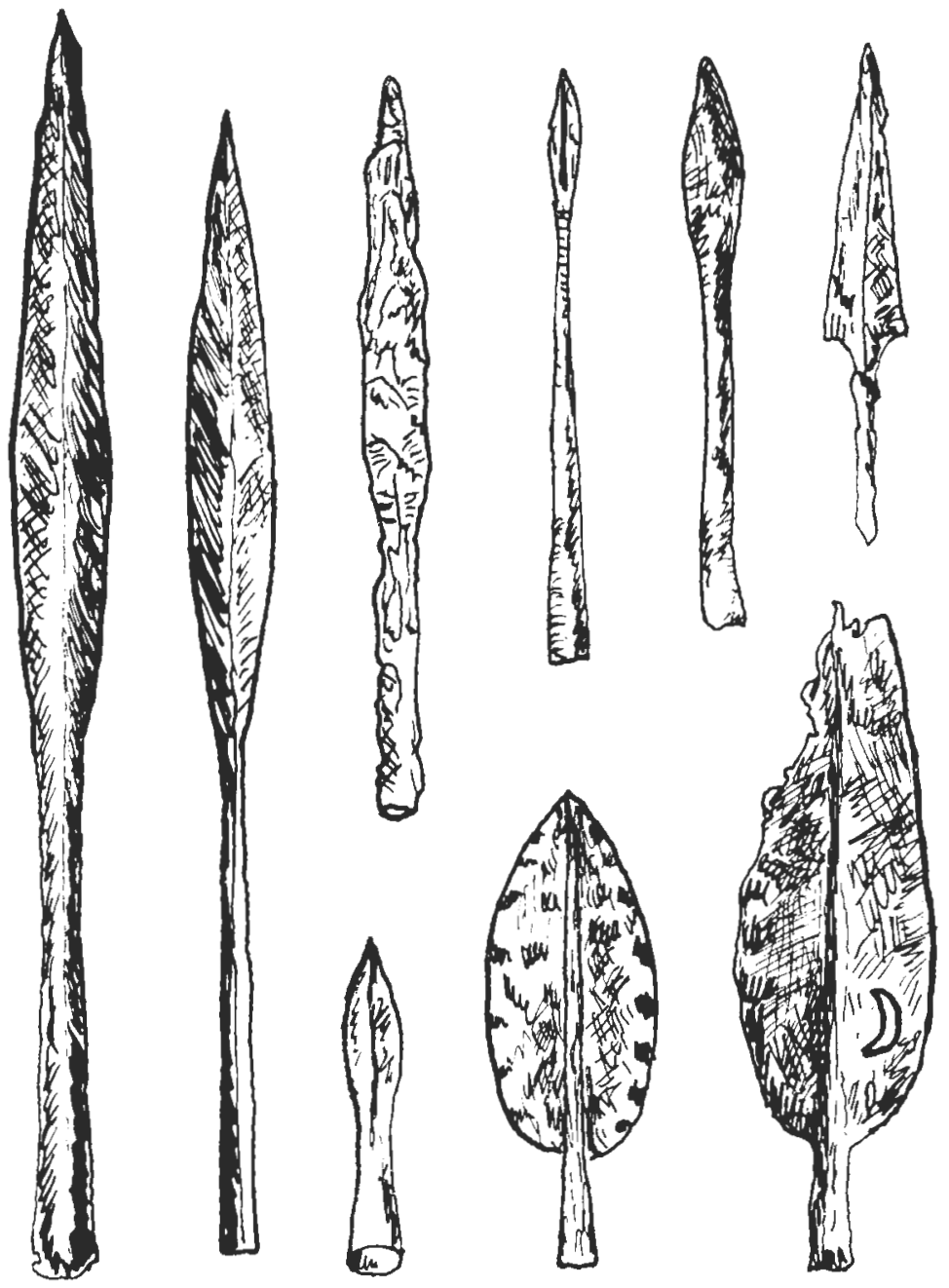

FIG. 5.-Lanzas y jabalinas estilo La Tène II (alemanas y francesas) (DF́cHeLETT'E: Manuel d'Archéologie, II, 3." parte). 
se usaran esporádicamente en el siglo XVI, respondiendo a una complicación manierista. La lanza más característica de La Tène es la de hoja muy ancha, bellamente ritmada, canon corto, longitud de unos $20 \mathrm{~cm}$. y anchura máxima casi de $15 \mathrm{~cm}$. Hojas de este tipo se han encontrado en Centroeuropa, Francia, los Países Bajos, etc. Dominaron, junto con hojas de canon alargado, hasta la introducción de los tipos impuestos por los francos: el angón y la lanza de tubo piramidal. Este tipo de tubo se ve,

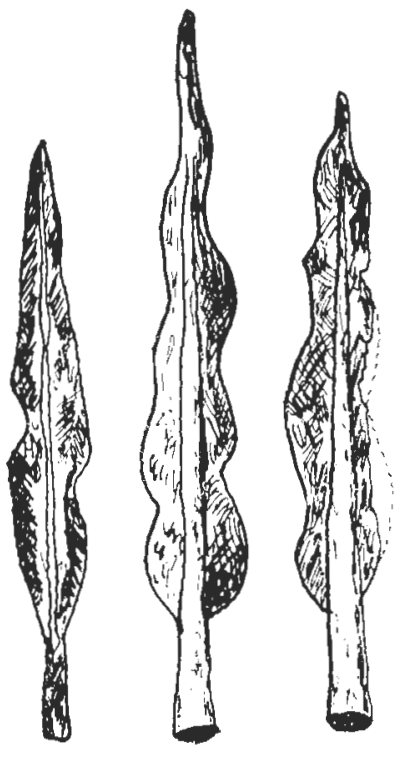

FIG. 6.-Lanzas flamigeras de La Tène II (de La Tène y Nimes) (DF́chelette: Manuel d'Archéglogie, II, 3:" parte).

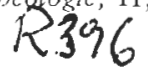

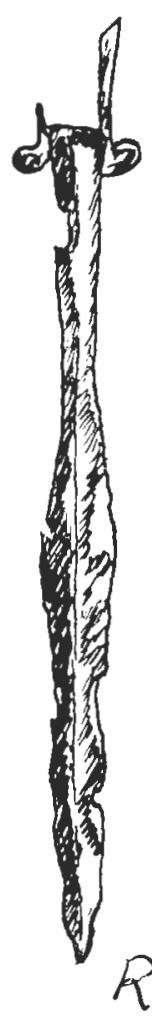

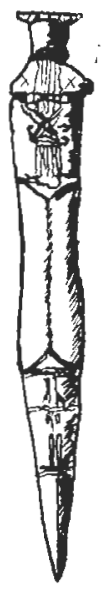

FIG. 8. - Lanza merovingia, e nfundada. Siglos v1vir d. de C.

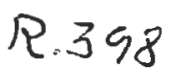

imperfectamente, en el ejemplo de la figura 7, tomado del catálogo de los museos alemanes de las comarcas del Rin: hoja de canon largo, bien ritmada, relativamente gruesa, y cuyos perfiles continúan en el tubo, a cuyo extremo se advierten una suerte de anillos que debieron servir de refuerzo para la fijación y seguramente también de tope. La idea de poner un tope a la lanza, es decir, un elemento transversal (o dos, a modo de 
aletas) que detenga la penetración del arma y permita retirarla al que la usa con más rapidez, no parece haberse impuesto, como el tubo piramidal, hasta finales del Imperio romano o la época de las migraciones. En todo caso, una forma embrionaria de aletas se encuentra en la lanza merovingia, enfundada (siglos vi-viI; Fig. 8), que la tradición denomina «Santa Lanza». El angón, citado antes de paso, es una adaptación franca del pilum, que se acerca a la jabalina; en realidad, es una larga flecha de mano, cuya punta tiene doble anzuelo (Fig. 9-b, tomada de Blankwaffen, de Seitz).

Por cierto, que vale la pena prestar gran atención a la serie propuesta aquí por el autor citado, pues es de suma utilidad para la clasificación de
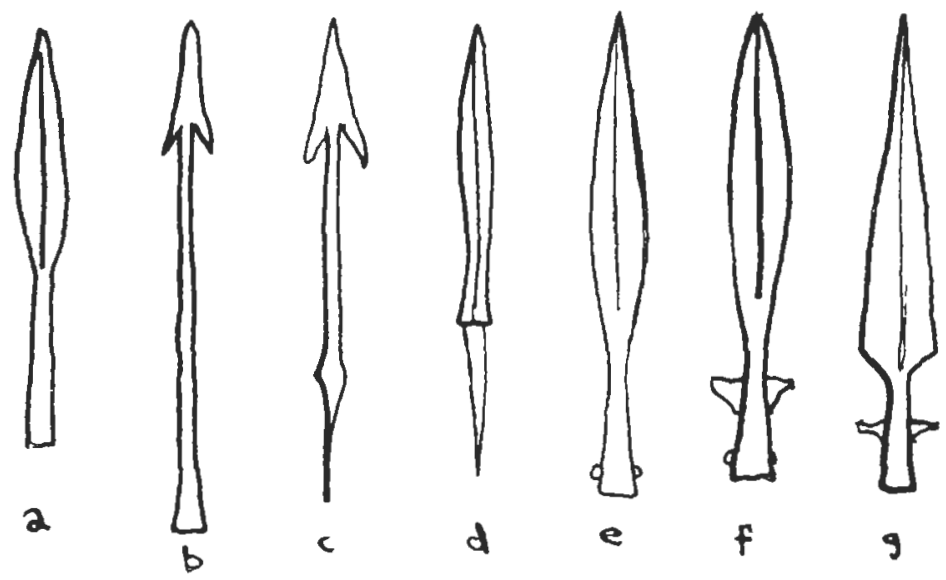

FIG. 9.-Tipologia de la lanza desde el siglo $V$ al XII, según HeriberT Seitz: Blankwaffen. a) Lanza franca. b) Angón franco. c) Tipo derivado del anterior. d) Siglos vil1-1x. e) Carolingia, siglos vıl1-ıx. f) y g) Prerrománicas, siglos VIII-XI.

\section{$R \cdot 399$}

lanzas altomedievales. En especial son interesantes los tipos $e, f$ y $g$, que reproducen lanzas con «aletas». Estas lanzas son típicas de un período relativamente concreto, que va desde el siglo viII al XI; corresponde a la expansión vikinga, $\mathrm{y}$, ciertamente, entre las lanzas halladas en tumbas de esta cultura hay tipos con aleta, así como en Inglaterra e Irlanda, siendo tan probable que fueran lanzas de los vikingos que allí desembarcaron desde finales del siglo viII como que fueran autóctonas. Estos tipos solían ser internacionales. Digamos algo sobre el aspecto material que dife- 
rencia la lanza de estos siglos con respecto a la de las tres grandes épocas anteriores: Hallstatt, La Tène y romano-franca. La lanza es más tubular en conjunto, es decir, incluyendo la hoja, más pesada y densa; el tubo es más largo y ancho, el hierro es más grueso. El arma tiene, con excepción de algunos tipos en los que pareció buscarse una particular finura realzada por la plata de los nielados, una fuerza mucho mayor que la del primer milenio antes de Jesucristo o que la de los siete primeros siglos de nuestra Era. En la figura 10 damos tres ejemplos de lanzas de los vikingos, especialmente bien ejecutadas, con adorno de plata; su «ritmo» parece proceder de lo hallstático, pero incorpora en un caso las aletas de tope.

Las lanzas románicas son una consecuencia de las de la etapa de los siglos VIII-XI; las aletas desaparecen por lo común o son sustituidas por

FIG. 10.-Lañas de los vikingos. $\mathrm{T}$ u bo s nielados con plata.
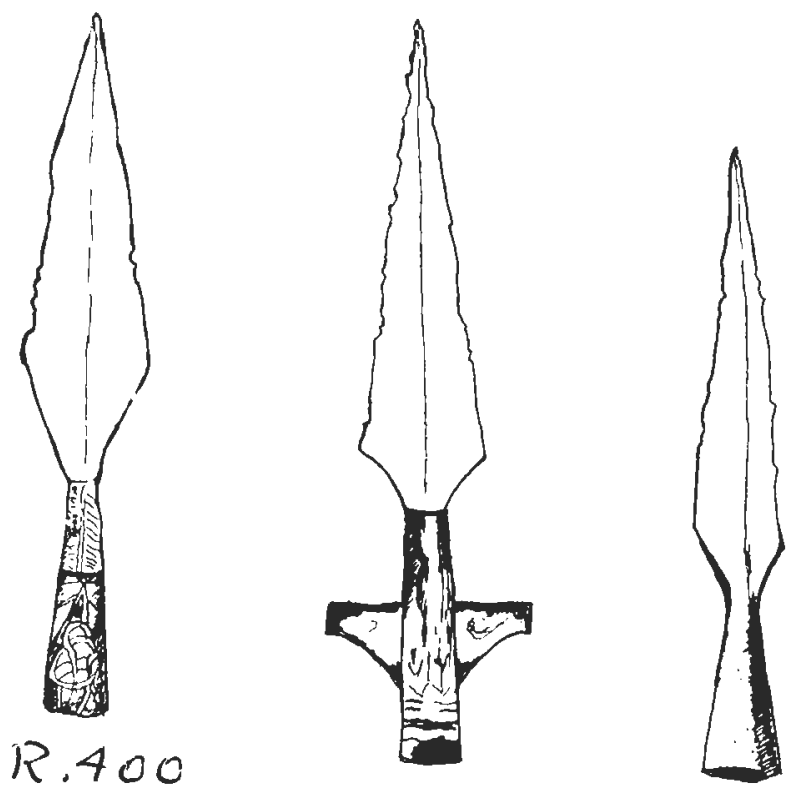

una doble punta complementaria, que convierte la lanza en un tridente, pero de hojas de largo muy desigual, siendo la del centro cuatro o cinco veces más larga que las laterales. La misión de estas puntas laterales sigue siendo la de detener, y es posible que estas armas fueran de caza y no de guerra, aunque nada autoriza a decretar que esto sea ley en todos los casos. La lanza románica es aún mayor que la de la etapa anterior y su 
tubularidad más intensa; suele medir de 35 a $45 \mathrm{~cm}$. de largo, incluyendo el tubo, bastante ancho y con cuatro agujeros a veces, en lugar de dos, para dar más vigor a la fijación. Todo ello presupone el aumento de fuerza en las armas defensivas (perfeccionamiento de cotas de malla, empleo

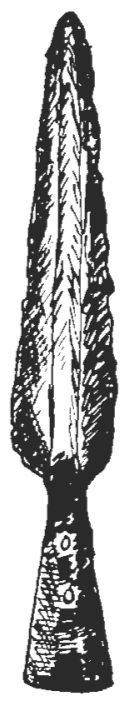

2.

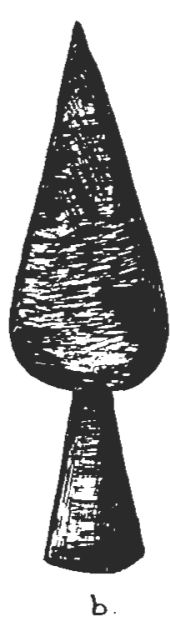

Fig. 11.-a) Lanza del siglo XII. b) Lanza del siglo XIV.

de largos escudos triangulares). En el período gótico, la lanza se mantiene casi igual, aunque destaca el tipo de hoja ancha (Fig. 11-a/b, respectivamente), que se ve en bastantes representaciones de caballeros comba-
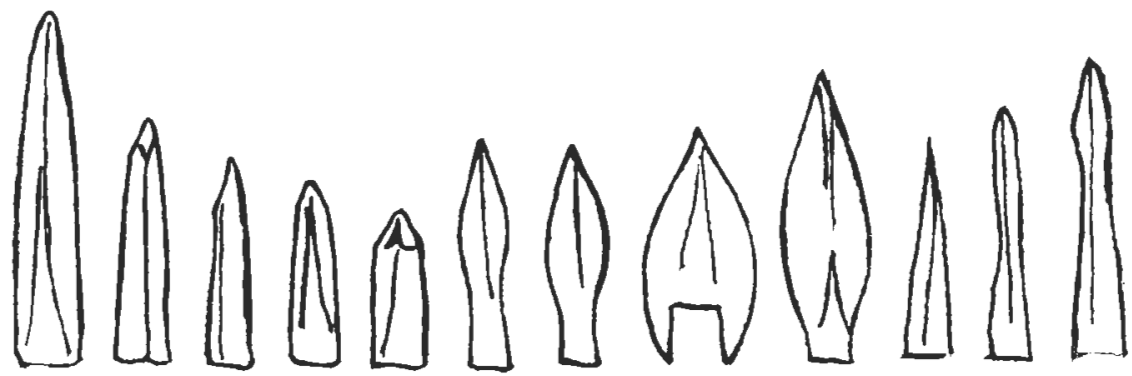

Fig. 12.-Hicrros de pica y de lanza. Siglo xvi (Armería Real, Madrid) (Enciclopedia Espasa).

14

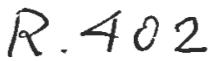


tiendo, de la época. La lanza pronto deriva hacia la pica, incluso cuando es manejada por jinetes, o bien adquiere formas complejas derivadas del «guisarme», cuando no retrocede a la hoja plana y larga $(50 \mathrm{~cm}$. y más), sobre todo desde 1450 , que es la antecesora directa de la partesana. En la Real Armería de Madrid se conservan hierros de lanzas del siglo Xvi (Fig. 12) muy diversos, que son - en las hojas más anchas- huecos, es decir, hechos con dos planchas unidas, pese a lo cual tienen considerable poder de penetración, tanto por la calidad de la técnica como por la adecuada forma del perfil. El tipo corto, de pica, que, en el fondo, responde al extremo del pilum romano, pero que ahora se fija a un asta de madera mediante largas tiras de hierro con tres a cinco agujeros de sujeción (Fi gura 13), demuestra que el poder de penetración depende más del impulso general de jinete y caballos lanzados a la carrera que de la hoja en sí. Con ello se inicia la decadencia de la lanza, que, sin embargo, aún produ-

Fig. 13.-Picas del siglo XV (HerIBERT SEITZ: Blankwaffen).
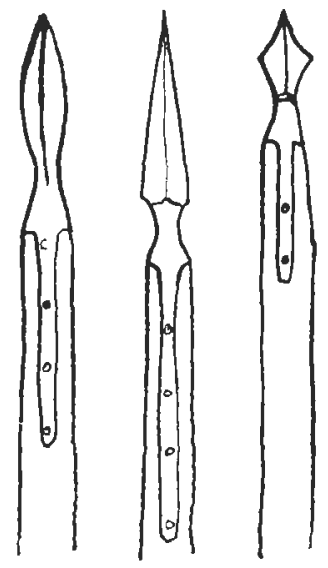

\section{$R .403$}

cirá - junto a los tipos complejos de la partesana, la alabarda, etc.ejemplares de gran belleza. Ya en la Baja Edad Media surge otra arma, o mejor, resurge: la jabalina. Para que su peso, en conjunto, sea más equilibrado, se hacen sus hierros de dos hojas unidas, es decir, son huecas y pesan poco, aunque pueden tener gran tamaño $(25 \mathrm{~cm}$. de largo por $10 \mathrm{~cm}$. de ancho). Estas hojas huecas se emplearán también como lanza en el siglo xvi. Seitz da ejemplos de ellas. En el xvir, lanzas de combate y de parada con frecuencia se confunden; se hacen con tubo corto enriquecido con perfiles y con hojas largas de dos mesas, que parecen de daga en ocasiones. Junto a estas formas perduran la pica y las otras formas. 
Obvio es decir que el aspecto de estas armas difiere más de las de la Baja Edad Media (sobre todo los siglos XII a XIV) que éstas de las anteriores. Su calidad es la de una herramienta moderna, la perfección de su acabado

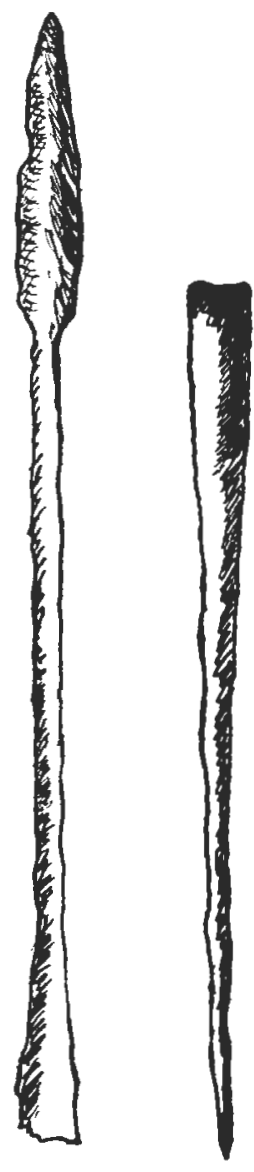

FIG. 14.-Punla y contera de lanza, precursora o derivada del pilum (MENÉNDEZ

Pidal: Historia de España, vol. II).

les quita el sabor que la rudeza de todos los períodos anteriores - unificados en esto- poseían.

Respecto a los pila, tipo especial de lanza con punta pequeña o mediana, que los romanos convirtieton en arma esencial de su infantería legionaria, sólo queremos decir escasas palabras. En España se han hallado tipos que pudieran llamarse «de transición» de la lanza al pilum 16 
(Fig. 14), pues la longitud de la contera y del tubo de hierro, sumadas, parecen corresponder al menos a una cuarta parte de la longitud del arma entera. En Italia se han encontrado, correspondiendo al siglo 111 antes de Jesucristo, armas precursoras del pilum más próximas a éste, como las halladas en Vulci y Montefortino, publicadas por Couissin, Les armes romaines (Fig. 15). El pilum será una estructura casi «científica» derivada de estas armas de asta férrea y dejará el hierro sólo para la mitad anterior, completando con una pequeña contera el asta de madera de la mitad baja (Fig. 16). Con esta punta pequeña y este largo, delgado y vibrante «cuello» de hierro se lograba perforar el escudo del adversario

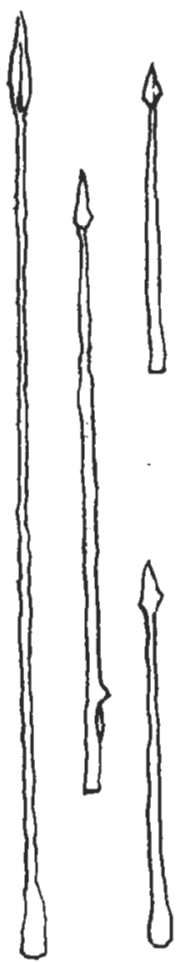

FIG. 15.-Armas precursoras del pilum (Vulci y Montefortino, siglo in a. de C.) (Couissin: Les armes ro-

$$
\text { R.405 }
$$

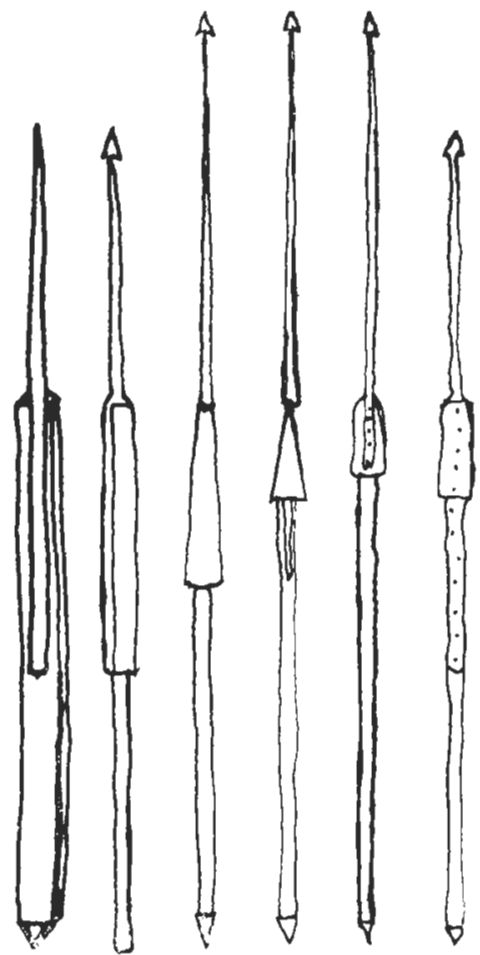

FIG. 16.-Pila romanos (según reconstrucciones de Rüstow. Cousssin: Les armes romaines) (corresponderían a descripciones de Polibio, siglo il a. de C.)

$$
R .406
$$


y llegarle al cuerpo, cosa imposible de conseguir con una lanza ordinaria - de estar el escudo separado del torso lo que permite el brazo del combatiente-- El pilum suele tener punta piramidal maciza, a veces en doble anzuelo, pero, en todos los casos, lo esencial es la larga vara metálica que afianza el golpe de la punta «siguiendo» tras de ella.

Hemos presentado un resumen de la evolución de la lanza, sumariamente considerada, a lo largo de más de dos mil años. Discúlpese al autor las forzosas lagunas y téngase en cuenta que su punto de vista ha sido más el del coleccionista que el del historiador. Pero adviértase también que sólo aquél se encuentra casi siempre con incógnitas, ya que en el mercado de antigüedades no suele hallarse nada clasificado ni siquiera por aproximación, sobre todo en lanzas, lo que aumenta el interés de su investigación.

\section{B I B L I O G R A F I A}

AвнмаN, Holger: The Vikings, Londres, 1961.

Coussin, Paul: Les armes romaines, París, 1926.

Déchelette, J.: Manuel d’Archéologie Pr. Cellique et Gallo-romaine, II, París, 1914. EWART OAKESHOTt: The Archaeology of Weapons, Londres, 1960.

Martin, Paul: Armes el Armures, París, 1967.

Meinánder, C. F.: Kivikirves Ja Hopearisli, Helsinki, 1961.

Menéndez Pidal, R.: España romana, en Historia de España, vol. II, Madrid, 1935 SEITZ, Heribert: Blankwaffen, I, Braunschweig, 1965.

SnODGRASS, Anthony: Early Greek Armour and Weapons, Edimburgo, 1964.

SNODGRass, Anthony: Arms and Armour of the Greeks, Londres, 1967.

Catálogo de los Museos del Rin. Revista Gladius, etc. 